\title{
Constant training in direct ophthalmoscopy
}

\author{
This article was published in the following Dove Press journal: \\ Advances in Medical Education and Practice \\ 14 August 2017 \\ Number of times this article has been viewed
}

\author{
Helen-Cara Younan \\ Rishi lyer \\ Janaki Natasha Desai \\ Faculty of Medicine, Imperial College \\ London, London, UK
}

\section{Dear editor}

We read with great interest the review by Ricci and Ferraz on the advances in training and practice in ophthalmoscopy simulation. ${ }^{1}$

As final year medical students, we have recently experienced direct ophthalmoscopy teaching and agree with the authors that "simulation is a helpful tool in ophthalmoscopy training". Indeed, in our experience, simulation is useful in teaching a wide variety of clinical skills including venepuncture, intravenous cannulation, and catheterization. We were taught all of these clinical skills in our first clinical year of study through use of simulation models. With regards to our direct ophthalmoscopy teaching, we were first taught to recognize the normal retina and different retinal pathologies using images, before practicing our technique and recognition of those images in a model similar to the THELMA (The Human Eye Learning Model Assistant) described by the authors. ${ }^{1}$

However, we feel that the use of simulation models alone is not enough to provide confidence and competency in direct ophthalmoscopy among medical students. The authors conclude that "constant training is a well-known strategy for skill enhancement", ${ }^{1}$ and we have found that a lack of constant training in direct ophthalmoscopy is evident. After learning venepuncture, cannulation, and catheterization on the simulation models, we were able to observe doctors performing these skills before performing them on patients either in the wards or in theatre. These are skills that we are constantly trained in across a wide variety of medical and surgical attachments. However, opportunities to observe and practice ophthalmoscopy during our attachments are more limited, and thus we are not continuing to use the skills we learn.

Ophthalmoscopy is an underperformed clinical examination; Dalay et al found that ophthalmoscopy was often not performed in many cases where it would have provided a useful diagnostic tool. ${ }^{2}$ This means that students have fewer opportunities to observe the examination in a clinical setting. This is a difficult problem to overcome in the short term; however, increased postgraduate training in the importance of the examination and in ophthalmoscopy techniques has been suggested as long-term solutions. ${ }^{2}$

Secondly, it is often difficult to find a working ophthalmoscope in an inpatient ward limiting opportunities for students to practice on patients. We suggest that medical education departments in hospitals should lend ophthalmoscopes to students in order to allow them to practice on patients.

Gupta and Lam found that a large proportion of medical students were not confident in various aspects of direct ophthalmoscopy and that self-confidence was significantly greater among students who practiced outside of formal teaching sessions. ${ }^{3}$ This supports our conclusion that although simulation models are useful the extent is limited,
Correspondence: Helen-Cara Younan Imperial College London, Sir Alexander Fleming Building, Prince Consort Road, Kensington, London SW7 2BB, UK

Tel +44 7778590724

Email helen-cara.younan12@imperial. ac.uk 
and students need to be encouraged to seize opportunities to practice on patients.

\section{Disclosure}

The authors report no conflicts of interest in this communication.

\section{References}

1. Ricci LH, Ferraz CA. Ophthalmoscopy simulation: advances in training and practice for medical students and young ophthalmologists. Adv Med Educ Pract. 2017;8:435-439.

2. Dalay S, Umar F, Saeed S. Fundoscopy: a reflection upon medical training?. Clin Teach. 2013;10(2):103-106.

3. Gupta RR, Lam WC. Medical students' self-confidence in performing direct ophthalmoscopy in clinical training. Can J Ophthalmol. 2006;41(2):169-174. 


\section{Authors' reply}

Lucas Holderegger Ricci ${ }^{1}$

Caroline Amaral Ferraz ${ }^{2}$

${ }^{1}$ Department of Ophthalmology, School of Medicine, Laureate International Universities, São Paulo, Brazil; ${ }^{2}$ Department of Ophthalmology, Federal University of São Paulo (UNIFESP), São Paulo, Brazil

\section{Correspondence: Lucas Holderegger Ricci}

Department of Ophthalmology, School of Medicine, Laureate International Universities, Rua Doutor Almeida Lima, 1.134, São Paulo, SP 03164-000, Brazil

Email lucholder@hotmail.com

\section{Dear editor}

We are delighted to see that our review on ophthalmoscopy simulation prompted a new discussion about the need for practice on real patients. As presented in our review, simulated training should be implemented with criteria as it can override patient safety protocols and individual comfort. Further, ophthalmoscopy remains an individual exam, since it is difficult for an outsider to evaluate examiner's techniques, field position, and correct anatomic identification. Although we mention new devices that allow simultaneous external evaluation, these seem to be not yet widely available.

Many students prefer to learn on real patients first, strengthening specific components after on a training device. Unfortunately, the art of ophthalmoscopy is quite vast, and even trained ophthalmologists still confront new findings throughout their career. Nevertheless, simulation appears to be effective in covering basic training and understanding, allowing students and young physicians to take each step individually and to advance according to their own confidence and interest. We welcome the suggestion given by Helen et al and we agree that simulation and real-patient practice must walk together, as either of these should never replace the other.

\section{Disclosure}

The authors report no conflicts of interest in this communication.

Dove Medical Press encourages responsible, free and frank academic debate. The content of the Advances in Medical Education and Practice 'letters to the editor' section does not necessarily represent the views of Dove Medical Press, its officers, agents, employees, related entities or the Advances in Medical Education and Practice editors. While all reasonable steps have been taken to confirm the content of each letter, Dove Medical Press accepts no liability in respect of the content of any letter, nor is it responsible for the content and accuracy of any letter to the editor.

\section{Publish your work in this journal}

Advances in Medical Education and Practice is an international, peerreviewed, open access journal that aims to present and publish research on Medical Education covering medical, dental, nursing and allied health care professional education. The journal covers undergraduate education, postgraduate training and continuing medical education including emerging trends and innovative models linking education, research, and health care services. The manuscript management system is completely online and includes a very quick and fair peer-review system. Visit http://www.dovepress.com/testimonials.php to read real quotes from published authors. 